\title{
Effect of silica sol of different routes on the properties of low cement castables
}

\author{
D DASPODDAR ${ }^{\dagger}$, SWAPAN Kr DAS* and P K DASPODDAR ${ }^{\dagger}$ \\ Refractories Division, Central Glass and Ceramic Research Institute, Kolkata 700 032, India \\ ${ }^{\dagger}$ Department of Chemical Technology, Calcutta University, Kolkata 700 009, India
}

MS received 27 June 2002; revised 23 October 2002

\begin{abstract}
Silica sols synthesized through different routes viz. inorganic, organic and ion-exchange routes, have been incorporated in the low cement alumina castable composition in various proportions and cast samples in the form of 2 inch cube briquettes were prepared. The cast briquettes after curing were subjected to heat treatment at various temperatures. The effect of different sources of such sols on the important physico-mechanical properties of the castables such as bulk density, apparent porosity, compressive strength, volume shrinkage and residual strength after spalling have been studied. Some of the selected samples were also subjected to microstructural evaluation. It is observed that silica sol synthesized through cation exchange routes has significant beneficial role on the properties of castable with $3 \%$ addition.
\end{abstract}

Keywords. Low cement $\mathrm{Al}_{2} \mathrm{O}_{3}$ castable; silica sol; ion exchange.

\section{Introduction}

Originally, all conventional refractory castables were bonded with calcium aluminate cement containing $\mathrm{CaO}$ content up to around 20\%. Low melting liquid phase formation in the system, $\mathrm{Al}_{2} \mathrm{O}_{3}-\mathrm{SiO}_{2}-\mathrm{CaO}$, including gehlenite and anorthite at working conditions significantly affects the high temperature properties of such high cement bonded conventional aluminous castable (Studart et al 1999). In addition to the above disadvantageous properties of high cement bonded conventional castable, it requires a high water demand on mixing, resulting low density and high porosity products (Kendall 1995). These drawbacks led to the development of low cement castable (LCC) containing $1.5-2.5 \% \mathrm{CaO}$. The principles behind this development of LCC and their improvement in regard to physical and thermomechanical properties have been widely reported (Clavaud et al 1983, 1984, 1985; Eguchi et al 1989; Masanyk et al 1993). In the beginning, calcium aluminate cement was partly replaced with ultrafine oxide powders such as $\mathrm{SiO}_{2}, \mathrm{Al}_{2} \mathrm{O}_{3}, \mathrm{TiO}_{2}, \mathrm{Cr}_{2} \mathrm{O}_{3}$ to produce coagulation bonding from the close contact of colloid particles by means of Vander Waal's force ( $\mathrm{Li}$ and $\mathrm{Ye} \mathrm{1992).} \mathrm{According} \mathrm{to}$ DLVO theory (Studart et al 1999), a repulsive force occurs when the particles approach each other due to overlap of electrostatic double layers. Gauckler et al (1999) and Studart et al (2002) recently reported that coagulation mechanism involve the modification of the

*Author for correspondence nature of forces acting among fine particles from typically repulsive to attractive forces. Dispersion technology using superfine oxide powder improve the quality of low cement castable including its flow properties. In a powder water dispersion system, electrostatic double layers form on the solid-liquid boundary. Their interaction force varies depending on the concentration of those ions determining the surface potential such as $\mathrm{H}^{+}$and $\mathrm{OH}^{-}$for metal oxides. Thus, the flow properties vary with $\mathrm{pH}$ in the aqueous solution. Amongst many kinds of superfine oxide powder, superfine powder of alumina and silica have been the basic materials in developing low cement castable (LCC). Superfine $\mathrm{Al}_{2} \mathrm{O}_{3}$ used in LCC must have particle diameter $4-5 \mu \mathrm{m}$ and specific surface area of around $1 \mathrm{~m}^{2} / \mathrm{g}$. Fumed silica of high purity is the most preferred available super fine silica successfully used in LCC compositions for many years. Superfine powder incorporated LCC formulations are available in many literatures (Myhre 1994; Kang et al 1995; Jones 1998) where effect of change in dispersion system, granulometry and particle morphology on flow behaviour are discussed. Recently different kinds of sols which form coagulation bonding have been tried as binder in low, ultralow and no cement bonded refractory castable compositions. Amongst them use of water based colloid (colloidal silica) in alumina containing castable is becoming most popular due to its superior thermo mechanical properties (Roy and Banerjee 1997; Banerjee 1998; Das et al 2002).

Many methods are known for synthesizing silica sol (Ailer 1959; Freidenberg and Khvorov 1989). In the present investigation, silica sols are synthesized by different 
routes and incorporated in different proportions to a low cement castable composition made from white fused alumina aggregate, microfine $\mathrm{Al}_{2} \mathrm{O}_{3}$ and high alumina cement. Effect of such silica sol addition on the important properties of low cement castable have been studied and discussed in this paper.

\section{Experimental}

\subsection{Synthesis of silica sol}

Silica sol of inorganic route (system A) was prepared by thorough mixing of $10 \% \mathrm{NH}_{4} \mathrm{Cl}$ and $10 \% \mathrm{Na}_{2} \mathrm{SiO}_{3}$ solutions. After removal of electrolyte, the sol was dispersed in aqueous medium by centrifugal action. System 'B' (silica sol of organic route) was prepared by mixing $1: 1$ volume of tetraethoxy silane and ethanol followed by slow addition of $1: 1 \mathrm{NH}_{4} \mathrm{OH}$ solution with constant stirring. The sol was dried and then dispersed in alcohol medium. Silica sol of ion-exchange route (system C) was prepared by passing $10 \% \quad \mathrm{Na}_{2} \mathrm{SiO}_{3}$ solution through $\mathrm{H}$-form of cation exchange column. The sol thus obtained was slowly evaporated to increase the solid content. $\mathrm{pH}$ of each sol was maintained at 8 by control addition of $1: 1 \mathrm{NH}_{4} \mathrm{OH}$ solution. It was observed during preparation of silica sol that below $\mathrm{pH} \mathrm{8,} \mathrm{complete} \mathrm{formation} \mathrm{of} \mathrm{silica}$ sol did not occur and it had gone into the solution. Above $\mathrm{pH} \mathrm{8,} \mathrm{there} \mathrm{was} \mathrm{agglomeration} \mathrm{of} \mathrm{sol} \mathrm{particles} \mathrm{and} \mathrm{gela-}$ taneous precipitation occurred which ultimately reduced the yield. In view of above, $\mathrm{pH}$ of each sol was maintained at 8 .

\subsection{Sample preparation and testing}

Major refractory raw materials such as white fused alumina (supplied by Carborundum Universal Ltd), high alumina cement (supplied by ACC Refractories), and microfine alumina (supplied by Indian Aluminium Co Ltd) were tested and intimately mixed following the batch formulation given in table 1 .

Test samples of $2.5 \mathrm{~cm}$ cube were prepared by vibrocasting technique following IS 10570 (1983). The samples were kept in saturated humidity for $24 \mathrm{~h}$ followed by water curing for another $24 \mathrm{~h}$ and then heat treated at different temperatures for $2 \mathrm{~h}$. Compressive strength of all the samples were measured using universal testing machine as per IS 1528: part 4 (1997). Bulk density, apparent porosity and linear changes were determined following standard methods. Spalling test was conducted by keeping the heat treated samples at $1000^{\circ} \mathrm{C}$ for $10 \mathrm{~min}$ followed by placing it in open air for next $10 \mathrm{~min}$ as per IS 1528: part 3 (1997). After 5 complete cycles, compressive strength of the samples were measured. Scanning electron microscopy was utilized using IEO electron microscope of model S440 to study the microstructure.

\section{Results and discussion}

The chemical analysis of the raw materials used in this investigation is provided in table 2. Gravimetric method was utilized to determine $\mathrm{SiO}_{2}$ and $\mathrm{Al}_{2} \mathrm{O}_{3}$ whereas $\mathrm{Fe}_{2} \mathrm{O}_{3}$, $\mathrm{CaO}$ and $\mathrm{MgO}$ were determined volumetrically (Hillebrand and Lundell 1953).

It may be seen from table 2 that white fused $\mathrm{Al}_{2} \mathrm{O}_{3}$ which is produced from fusion of calcined alumina has a very high purity $\left(99.38 \mathrm{wt} \% \quad \mathrm{Al}_{2} \mathrm{O}_{3}\right)$. Microfine $\mathrm{Al}_{2} \mathrm{O}_{3}$ used in the castable formulation is also of purer variety (99.58 wt $\% \mathrm{Al}_{2} \mathrm{O}_{3}$ ) with $6-8 \mu \mathrm{m}$ average particle diameter and $\alpha-\mathrm{Al}_{2} \mathrm{O}_{3}$ content more than $95 \%$. High alumina cement was analysed by $\mathrm{X}$-ray diffraction and found to consist of $\mathrm{CA}$ and $\mathrm{CA}_{2}$ as major, $\mathrm{C}_{12} \mathrm{~A}_{7}(\mathrm{C}=\mathrm{CaO}$, $\mathrm{A}=\mathrm{Al}_{2} \mathrm{O}_{3}$ ) and $\alpha$-alumina as minor phases (Das et al 1997). The specific surface area measured by the air permeability method was around $3150 \mathrm{~cm}^{2} / \mathrm{g}$.

Table 1. Batch formulation.

\begin{tabular}{|c|c|c|c|c|c|c|c|}
\hline \multirow[b]{3}{*}{ Sample code } & & \multicolumn{6}{|c|}{ Raw materials (wt\%) } \\
\hline & & \multicolumn{3}{|c|}{ White fused alumina } & \multirow{2}{*}{$\begin{array}{l}\text { High alumina } \\
\text { cement }\end{array}$} & \multirow{2}{*}{$\begin{array}{l}\text { Microfine } \\
\mathrm{Al}_{2} \mathrm{O}_{3}\end{array}$} & \multirow[b]{2}{*}{ Silica sol } \\
\hline & & $\mathrm{C}$ & $\mathrm{M}$ & $\mathrm{F}$ & & & \\
\hline Without sol & I & 50 & 20 & 13 & 7 & 10 & - \\
\hline \multirow{3}{*}{$\begin{array}{l}\text { System A } \\
\quad \text { (Sol of inorganic route) }\end{array}$} & IA & 50 & 20 & 13 & 7 & 9 & 1 \\
\hline & IIA & 50 & 20 & 13 & 7 & 7 & 3 \\
\hline & IIIA & 50 & 20 & 13 & 7 & 5 & 5 \\
\hline \multirow{3}{*}{$\begin{array}{l}\text { System B } \\
\text { (Sol of organic route) }\end{array}$} & IB & 50 & 20 & 13 & 7 & 9 & 1 \\
\hline & IIB & 50 & 20 & 13 & 7 & 7 & 3 \\
\hline & IIIB & 50 & 20 & 13 & 7 & 5 & 5 \\
\hline \multirow{3}{*}{$\begin{array}{l}\text { System C } \\
\quad \text { (Sol of ion exchange route) }\end{array}$} & IC & 50 & 20 & 13 & 7 & 9 & 1 \\
\hline & IIC & 50 & 20 & 13 & 7 & 7 & 3 \\
\hline & IIIC & 50 & 20 & 13 & 7 & 5 & 5 \\
\hline
\end{tabular}

$\mathrm{C}=$ coarse, $\mathrm{M}=$ medium, $\mathrm{F}=$ fine. 
Table 3 shows that compressive strength values are increased by adding silica sol and the values are maximum in case of systems $\mathrm{A}$ and $\mathrm{C}$. The ultrafine particles are dispersed between the refractory grains and formed a coagulated hydraulic bond in presence of silica sol which might have improved the strength. No significant reduction in compressive strength value at intermediate temperature of heating was observed. The reaction product of silica sol with hydrated calcium aluminates during hydration of LCC arrests strength retrogression both at ambient and intermediate temperatures during heating of castable. This phenomenon was also observed by Midgley (1980) who found this reaction product as stratlingite $\left(\mathrm{CaO} \cdot \mathrm{Al}_{2} \mathrm{O}_{3} \cdot \mathrm{SiO}_{2} \cdot \mathrm{H}_{2} \mathrm{O}\right)$.

For comparison, the compressive strength results of $1500^{\circ} \mathrm{C}$ heated samples are graphically represented in figure 1. It may be observed from this figure that the compositions with silica sol of ion exchange route (system C) gives better strength than systems A and B. Strength of system B is inferior to both A and C. It may also be seen that $3 \%$ silica sol in all the three cases gives the optimum results. Probably, it is due to the simultaneous effect of coagulation bonding contributed by silica sol and hydraulic bonding contributed by calcium aluminate cement hydrated in presence of water coming from silica sol. In case of less sol $(1 \%)$, coagulation bonding is incomplete and in case of more sol $(5 \%)$ and reduced microfine alumina content, the matrix becomes very porous with inadequate compactness. Hence combination of $3 \%$ silica sol and $7 \%$ microfine $\mathrm{Al}_{2} \mathrm{O}_{3}$ may be consi-

Table 2. Chemical analysis of the raw materials.

\begin{tabular}{lccc}
\hline & \multicolumn{3}{c}{ Raw materials } \\
\cline { 2 - 4 } $\begin{array}{l}\text { Chemical } \\
\text { constituents (wt } \%)\end{array}$ & $\begin{array}{c}\text { White fused } \\
\mathrm{Al}_{2} \mathrm{O}_{3}\end{array}$ & $\begin{array}{c}\mathrm{High} \mathrm{Al}_{2} \mathrm{O}_{3} \\
\text { cement }\end{array}$ & $\begin{array}{c}\text { Microfine } \\
\mathrm{Al}_{2} \mathrm{O}_{3}\end{array}$ \\
\hline $\mathrm{Al}_{2} \mathrm{O}_{3}$ & $99 \cdot 38$ & $73 \cdot 30$ & $99 \cdot 58$ \\
$\mathrm{SiO}_{2}$ & $0 \cdot 13$ & 0.95 & - \\
$\mathrm{Fe}_{2} \mathrm{O}_{3}$ & $0 \cdot 12$ & $0 \cdot 20$ & - \\
$\mathrm{CaO}$ & - & 24.50 & - \\
$\mathrm{MgO}$ & - & 0.45 & - \\
Loss on ignition & $0 \cdot 34$ & 0.35 & $0 \cdot 32$ \\
\hline
\end{tabular}

dered as optimum additive content for getting all desirable properties. The compressive strength was found to be maximum at $1500^{\circ} \mathrm{C}$ for all the compositions. This may be due to the reason that when fine particles of amorphous silica generated during heating reacts with microfine alumina present in the castables, a network of mullite needles develops at higher temperatures which strengthen the matrix. The similar observation was also made by Pivinskii (1995). The results of variation in bulk density, apparent porosity and linear changes in the temperature range $1200-1500^{\circ} \mathrm{C}$ are given in table 4 .

It may be observed that $\mathrm{BD}$ increases with heating due to gradual formation of ceramic bond and the value is maximum at $1500^{\circ} \mathrm{C}$ for all the compositions. Due to increase in $\mathrm{BD}$, the AP value expectedly decreases. The percent linear changes was found to be within tolerance limits. The value is below $0.5 \%$ at $1200^{\circ} \mathrm{C}$ and below $1.5 \%$ at higher temperatures. Further the results of table 4 have shown that addition of $3 \%$ silica sol of ion exchange route (system C) favourably influenced all these properties.

Table 5 indicates the residual strength after spalling test of heat treated samples. It is found that strength retention is much better in case of system $\mathrm{C}$.

Scanning electron micrographs of selected samples are shown in figures $2 \mathrm{a}-\mathrm{d}$. It is found that better compactness

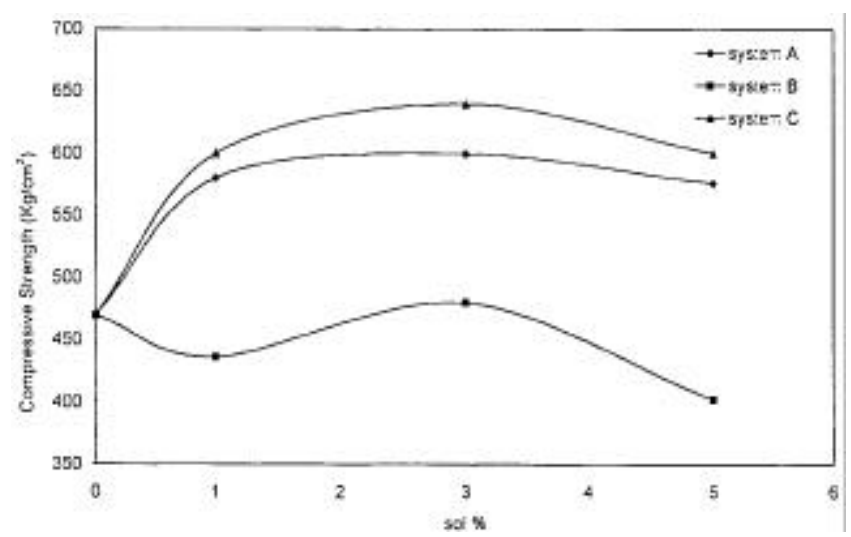

Figure 1. Compressive strength of $1500^{\circ} \mathrm{C}$ heated samples vs sol\% of various routes.

Table 3. Compressive strength in relation to heating temperature.

\begin{tabular}{lcccccccccc}
\hline & \multicolumn{8}{c}{ Compressive strength $\left(\mathrm{kg} / \mathrm{cm}^{2}\right)$} \\
\cline { 2 - 10 } & \multicolumn{10}{c}{ Sample code } \\
\cline { 2 - 10 } Temperature $\left({ }^{\circ} \mathrm{C}\right)$ & I & IA & IIA & IIIA & IB & IIB & IIIB & IC & IIC & IIIC \\
\hline 110 & 339 & 400 & 430 & 415 & 260 & 276 & 226 & 330 & 380 & 320 \\
800 & 245 & 410 & 426 & 405 & 305 & 321 & 310 & 418 & 426 & 402 \\
1200 & 207 & 395 & 402 & 380 & 286 & 298 & 290 & 390 & 398 & 386 \\
1400 & 245 & 430 & 456 & 402 & 370 & 396 & 310 & 486 & 502 & 480 \\
1500 & 470 & 580 & 600 & 576 & 436 & 480 & 402 & 600 & 640 & 600 \\
\hline
\end{tabular}


Table 4. Bulk density (BD), apparent porosity (AP) and linear changes (LC) of castables in relation to heating temperatures.

\begin{tabular}{|c|c|c|c|c|c|c|c|c|c|c|c|}
\hline \multirow[b]{2}{*}{$\begin{array}{l}\text { Heating } \\
\text { temperature }\left({ }^{\circ} \mathrm{C}\right)\end{array}$} & \multirow[b]{2}{*}{ Properties } & \multicolumn{10}{|c|}{ Sample code } \\
\hline & & I & IA & IIA & IIIA & IB & IIB & IIIB & IC & IIC & IIIC \\
\hline \multirow[t]{3}{*}{1200} & $\mathrm{BD}\left(\mathrm{g} / \mathrm{cm}^{3}\right)$ & $2 \cdot 65$ & $2 \cdot 55$ & $2 \cdot 61$ & $2 \cdot 58$ & $2 \cdot 55$ & $2 \cdot 58$ & $2 \cdot 55$ & $2 \cdot 65$ & $2 \cdot 70$ & $2 \cdot 65$ \\
\hline & $\mathrm{AP}(\%)$ & $25 \cdot 9$ & $24 \cdot 2$ & $23 \cdot 9$ & $24 \cdot 5$ & $25 \cdot 3$ & $25 \cdot 0$ & $25 \cdot 8$ & $23 \cdot 2$ & $22 \cdot 8$ & $23 \cdot 0$ \\
\hline & LC\% (-ve) & $0 \cdot 28$ & $0 \cdot 26$ & $0 \cdot 28$ & $0 \cdot 26$ & $0 \cdot 30$ & $0 \cdot 32$ & $0 \cdot 35$ & $0 \cdot 26$ & $0 \cdot 28$ & $0 \cdot 29$ \\
\hline \multirow[t]{3}{*}{1400} & $\mathrm{BD}\left(\mathrm{g} / \mathrm{cm}^{3}\right)$ & $2 \cdot 75$ & $2 \cdot 78$ & $2 \cdot 80$ & $2 \cdot 70$ & $2 \cdot 65$ & $2 \cdot 70$ & $2 \cdot 68$ & $2 \cdot 78$ & $2 \cdot 84$ & $2 \cdot 82$ \\
\hline & $\mathrm{AP}(\%)$ & $23 \cdot 5$ & $22 \cdot 6$ & $21 \cdot 8$ & $22 \cdot 0$ & $22 \cdot 80$ & $22 \cdot 0$ & $22 \cdot 5$ & $19 \cdot 0$ & $18 \cdot 5$ & $18 \cdot 8$ \\
\hline & LC\% (-ve) & $1 \cdot 05$ & $1 \cdot 21$ & $1 \cdot 25$ & $1 \cdot 28$ & $1 \cdot 26$ & $1 \cdot 22$ & $1 \cdot 25$ & $1 \cdot 21$ & $0 \cdot 98$ & $1 \cdot 25$ \\
\hline \multirow[t]{3}{*}{1500} & $\mathrm{BD}\left(\mathrm{g} / \mathrm{cm}^{3}\right)$ & $2 \cdot 82$ & $2 \cdot 85$ & $2 \cdot 90$ & $2 \cdot 80$ & $2 \cdot 70$ & $2 \cdot 78$ & $2 \cdot 72$ & $2 \cdot 90$ & $2 \cdot 92$ & $2 \cdot 88$ \\
\hline & $\mathrm{AP}(\%)$ & $22 \cdot 6$ & $18 \cdot 8$ & $18 \cdot 6$ & $19 \cdot 0$ & $19 \cdot 1$ & $19 \cdot 0$ & $19 \cdot 5$ & $12 \cdot 5$ & $12 \cdot 0$ & $12 \cdot 8$ \\
\hline & LC\% (-ve) & $1 \cdot 20$ & $1 \cdot 28$ & $1 \cdot 26$ & $1 \cdot 22$ & $1 \cdot 30$ & $1 \cdot 35$ & $1 \cdot 38$ & $1 \cdot 28$ & $1 \cdot 26$ & 1.29 \\
\hline
\end{tabular}

Table 5. Residual strength (\%) after spalling test in relation to heating temperature.

\begin{tabular}{|c|c|c|c|c|c|c|c|c|c|c|}
\hline \multirow[b]{2}{*}{ Temperature $\left({ }^{\circ} \mathrm{C}\right)$} & \multicolumn{10}{|c|}{ Residual strength (\%) } \\
\hline & I & IA & IIA & IIIA & IB & IIB & IIIB & IC & IIC & IIIC \\
\hline 1200 & $81 \cdot 8$ & $83 \cdot 6$ & $84 \cdot 6$ & $80 \cdot 8$ & $78 \cdot 0$ & $78 \cdot 8$ & $78 \cdot 2$ & $86 \cdot 6$ & $88 \cdot 0$ & $86 \cdot 8$ \\
\hline 1400 & $70 \cdot 5$ & $78 \cdot 8$ & $79 \cdot 0$ & $78 \cdot 5$ & $70 \cdot 2$ & $70 \cdot 8$ & $70 \cdot 2$ & $84 \cdot 4$ & $86 \cdot 0$ & $84 \cdot 8$ \\
\hline 1500 & $78 \cdot 0$ & $80 \cdot 5$ & $82 \cdot 0$ & $83 \cdot 1$ & $75 \cdot 0$ & $76 \cdot 8$ & $75 \cdot 2$ & $86 \cdot 8$ & 88.5 & $87 \cdot 8$ \\
\hline
\end{tabular}
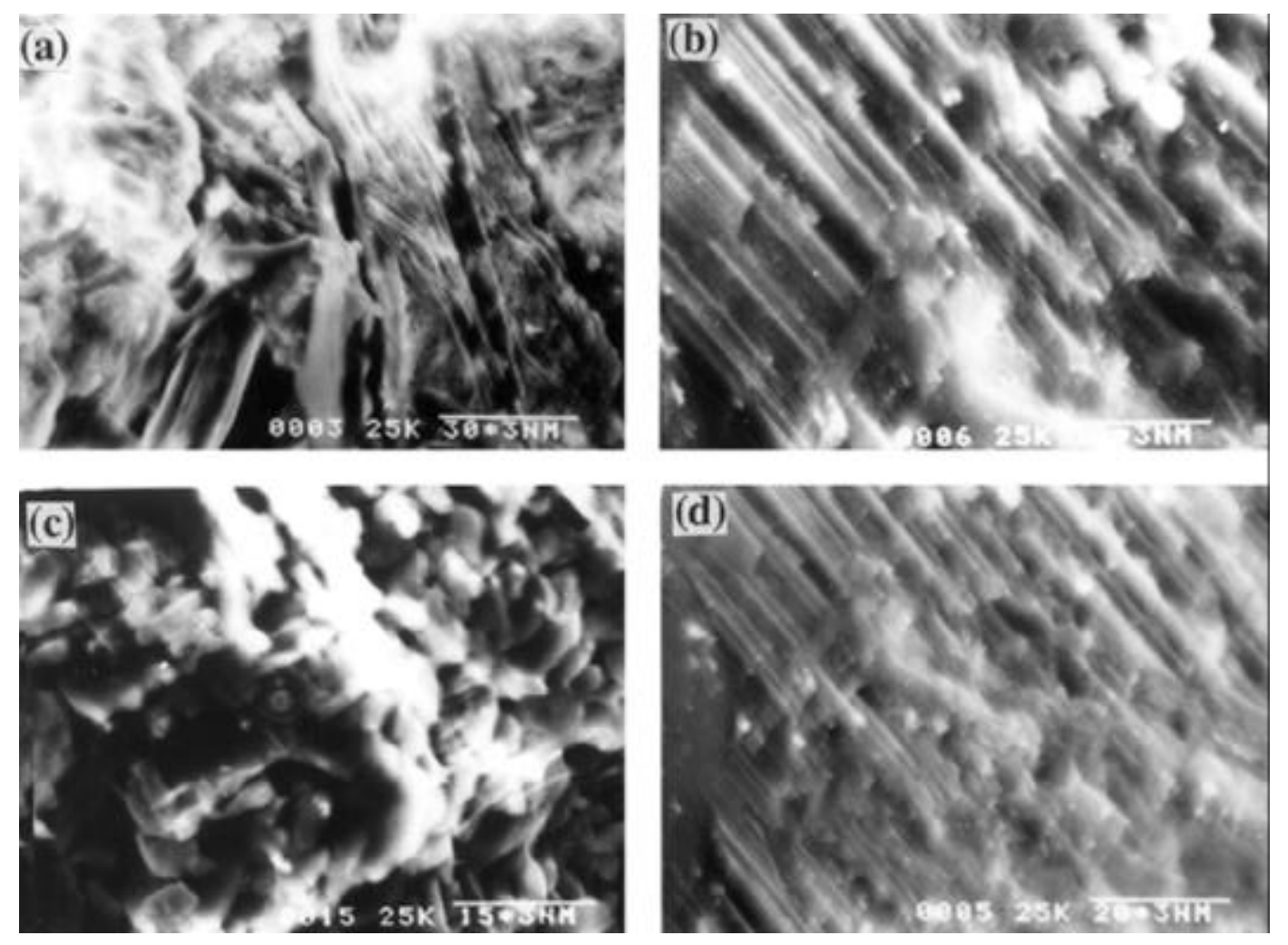

Figure 2. SEM photographs of samples heat treated at $1500^{\circ} \mathrm{C}$ : (a) sample without silica sol, (b) sample with silica sol of system A (inorganic route), (c) sample with silica sol of system B (organic route) and (d) sample with silica sol of system C (ion-exchange route). 
of matrix with uniform distribution of mullite crystals occur in case of system C. It may be said that cation exchange route generates silica sol of smaller particle size which helps ceramic bond formation through mullitization in a more uniform way.

\section{Conclusions}

From the present investigation, the following conclusions are drawn:

(I) Silica sols of inorganic and ion exchange routes improve the desirable properties of castable significantly in comparison to silica sol of organic route.

(II) In both systems A and C silica sol is found to be more beneficial when the content is $3 \%$.

(III) Considering all the properties and microstructure of castables, silica sol of cation exchange route may be considered more effective.

\section{Acknowledgement}

The authors wish to thank Prof. N K Mitra, Department of Chemical Technology, Calcutta University, Kolkata, for his help and suggestions during the course of the present investigation.

\section{References}

Alier R K 1959 Colloid chemistry of silica and silicates (Moscow, Russia: Izd-vo Lit-ry po str-vu)

Banerjee S 1998 A comprehensive hand book on monolithic refractories (Westerville O H: Am. Ceram Soc. Publication)
Clavaud B, Kiehl J P and Schmidt-Whitley R D 1983 Proceedings int. conference on refractories (Tokyo, Japan: Technical Association of Refractories)

Clavaud B, Kiehl J P and Radal J P 1984 Proceedings of the annual session of Am. Ceram. Soc. (Pittsburgh, USA: American Ceramic Society)

Clavaud B, Kiehl J P and Radal J P 1985 Proceedings of the annual session of Am. Ceram. Soc. (Columbus, USA: American Ceramic Society)

Das S K, Kumar S and Daspoddar P K 1997 Ind. Ceram. 1717

Das S K, Mondal P K and Mukherjee S N 2002 Indian Patent CSIR file No. NF-9

Eguchi T, Takita I, Yoshitomi J, Kiritani S and Sato M 1989 Taikabutsu Overseas 910

Freidenberg A S and Khvorov N V 1989 Refractories 30614

Gauckler L J, Graule T J and Baader F A 1999 Mater. Chem. Phys. 6178

Hillebrand W F and Lundell G E F 1953 Applied inorganic analysis (New York: John Wiley \& Sons) 2nd ed.

Jones V 1998 Ceramic Ind. 49

Kang K H, Cha C H and Yong S Y 1995 Proceedings of UNITECR'95 (Kyoto, Japan: Technical Association of Refractories publication)

Kendall T 1995 Ind. Mineral 33

$\mathrm{Li} \mathrm{Z}$ and Ye G 1992 Interceram 41169

Masanyk J S, Steinke R A and Videtto R B 1993 Proceedings of UNITECR'93 (Sao Paulo, Brazil: Brazil Ceramic Soc. Publication)

Midgley H G 1980 Proceedings of 7th Congress Chem Cement (Paris: Akademia Books International) p. 68

Myhre B 1994 Proceedings of Am. ceram. soc. annual refractory symposium (St Louis, Missouri, USA: Am. Ceram. Soc. Publication)

Pivinskii I Y E 1995 Refractories 363

Roy A K and Banerjee G 1997 Indian Patent file No. 909/DEL

Studart A R, Zhong W and Pandolifelli V C 1999 Am. Ceram. Soc. Bull. 65

Studart A R, Valenzuela F A O, Pandolfelli V C, Tervoort E and Gauckler L J 2002 Am. Ceram. Soc. Bull. 8126 